\title{
Dos siglos del comercio gaditano a través de los poderes notariales $(1650-1850)$
}

\section{Ma DOLORES LOZANO SALADO}

\section{INTRODUCCION}

El reconocimiento de la documentación notarial como una fuente con valor por sí misma para la historia social y para la historia económica ha sido mérito principalmente de los historiadores modernistas de la segunda mitad de nuestro siglo. Este proceso de valoración de los fondos notariales ha exigido, desde luego, un esfuerzo considerable, ya que las dificultades de manejo que ofrece una fuente tan masiva y voluminosa ha requerido un uso nuevo de la misma, un empleo sistemático basado en los análisis seriados y cuantificados de las escrituras notariales que permita sacar partido de su masa y de su volumen. Esta nueva forma de trabajar la documentación de origen notarial se ha perfeccionado notablemente en las últimas décadas, pudiendo afirmarse en la actualidad que el interés por el documento único y singular, que caracterizó a las primeras incursiones de los historiadores en esta masa documental, ha sido desplazado definitivamente en beneficio de las múltiples posibilidades que ofrece el tratamiento masivo y sistemático de dicha información.

Dentro de los diversos campos de aplicación de la documentación notarial, la historia del comercio, sobre la que ahora recae nuestra atención, cuenta con numerosos ejemplos de utilización de protocolos notariales, no siempre empleados con carácter de fuente sustantiva de la investigación, pero sí muchas veces con carácter complementario o con carácter de fuentes de sustitución (1). Además, los fondos notariales ofrecen las únicas posibilidades de estudio de las actividades desarrolladas por el pequeño comercio, que por su modestia y

(1) Podríamos citar múltiples obras sobre historia del comercio que han utilizado como fuentes básicas los protocolos notariales. Sin duda, sería una labor bastante prolija, por lo que nos limitaremos a apuntar solamente algunas de las más desta- 
escasa organización técnica no suele emanar archivos propios ni dejar huellas apreciables en los grandes registros oficiales.

Entre la amplia tipología de las escrituras notariales hemos optado en este trabajo por un tipo documental que no despierta demasiados afectos entre los historiadores: los poderes. Sin duda, son las escrituras más abundantes en un fichero de protocolos; sin embargo, muchos de ellos están concebidos en términos tan generales que ofrecen una información mínima, circunstancia que ha provocado que su interés para la investigación aparezca, en principio, bastante limitado. Pero no siempre es así; otros muchos detallan, además de las partes litigantes, las causas en que se litiga y otros datos adicionales al asunto principal. Es por ello que este tipo documental, si bien no permite un estudio en profundidad de ningún tema en concreto, sí aporta una rica información complementaria en multitud de investigaciones, máxime teniendo en cuenta la gran variedad de materias que abarca. Como señala el profesor Eiras Roel, el fichero de poderes es un saco sin fondo en el que el investigador paciente podrá encontrar valiosa información complementaria para cualquiera de los temas de estudio sugeridos por el resto de la documentación notarial (2).

Después de la afirmación anterior, resulta obvio que somos conscientes de que un estudio del comercio gaditano en las fechas citadas no puede realizarse exclusivamente a partir de dicha fuente. Sin embargo, aunque no añadimos nada definitivo a lo que hasta ahora han aportado los distintos estudios realizados sobre el tema, creemos que sí puede resultar interesante la aportación a nivel metodológico, pues muestra la validez para el estudio de la historia económica y, en concreto, de la historia del comercio, de los poderes, una fuente nota-

cadas. Por ejemplo, el estudio de R. GASCON: Grand commerce et vie urbaine au XVTe siècle. Lyon et ses marchands, París, 1971; el de CH. CARRIERE: Négociants marseillais au XVIIIe siècle. Contribution à l'étude des économies maritimes, Marseille, 1973; el de P. GOUBERT: Familles marchandes sous l'ancien régime: Les Danse et les Motte de Beauvais, París, 1959; y el de F. BAYARD: "Les Bonvisi, marchands banquiers à Lyon, 1575-1629", en Annales, 26, 6, 1971 (este trabajo utiliza, entre otras escrituras, los poderes, que le sirven para reconstruir el espacio europeo de los Bonvisi como mercaderes y como banqueros).

Por lo que respecta a nuestro país, en las dos últimas décadas han proliferado los estudios relacionados con el comercio que hacen un uso más intensivo de la documentación notarial. El empleo de estos fondos caracteriza principalmente la labor de los profesores Vázquez de Prada y Pere Molas. Igualmente, merecen destacarse en tal sentido los trabajos de A. GARCIA-BAQUERO, C. MARTINEZ SHAW, J. MAR'TINEZ GIJON Y M.J. ALVAREZ PANTOJA.

(2) Vid. EIRAS ROEL, A.: Tipología documental de los protocolos gallegos. Santiago de Compostela, 1983, pp. 21-43. 
rial, como hemos dicho, algo denostada entre los estudiosos de estas líneas de investigación.

Para el trabajo que aquí presentamos hemos elegido una cronología que abarca dos centurias a caballo entre el siglo XVI y el XIX: 1650 y 1850. En segundo lugar, hemos seleccionado entre los fondos pertenecientes a Cádiz del Archivo Histórico Provincial una Notaría -la 19y hemos realizado cinco catas, una cada cincuenta años a partir de 1650 (3). En concreto, hemos recogido y analizado todos los poderes relacionados con la actividad comercial en los años escogidos entre ambas fechas. No obstante, a fin de captar la imagen más completa del comercio y el comerciante gaditano, hemos recogido también poderes no relacionados directamente con la actividad mercantil pero que fueron otorgados por comerciantes.

En total, son 133 los poderes que nos van a servir de base para el estudio estadístico-descriptivo que realizaremos a continuación. 1650, 1750 y 1800 son los años con mayor número de información, especialmente los dos últimos (4). Por otra parte, resulta curiosa la escasez de poderes en 1700 -solamente cinco-, circunstancia, además, difícil de explicar, pues si bien sabemos que el tráfico comercial de España con Indias experimentó un descenso durante los primeros años del siglo XVIII (5), nos consta, igualmente, que otras notarías observan en ese mismo año un gran número de poderes de carácter comercial, relacionados precisamente con el comercio americano. Por ello, nos inclinamos a pensar que la pobreza de documentos de este legajo -que, por lo demás, es general- se debe más a la escasa demanda de la notaría en ese momento que al supuesto descenso de las actividades mercantiles. El reducido número de poderes en 1850 -siete- entra dentro de lo que era de esperar, puesto que por esas fechas el comercio gaditano y la propia ciudad habían entrado ya en una etapa de franca y abierta decadencia, motivada, como es sabido, por los importantes acontecimientos que acompañaron el nacimiento de la centuria: las

(3) Año 1650: Leg. 4.405, Not. Francisco de Soto.

Año 1700: Leg. 4.443, Not. Juan Ludres Bueno.

Año 1750: Legs. 4.480 y 4.481, Not. Matías Rodríguez.

Año 1800: Legs. 4.555, 4.556, 4.557, 4.558, 4.559 y 4.560. Not. Ramón García de Meneses.

Año 1850: Leg. 4.628. Not. Cayetano Grotta.

(4) Año 1650: 17 poderes.

Año 1750: 58 poderes.

Año 1800: 47 poderes.

(5) Vid. M.C. BORREGO PLA, "Tráfico comercial de España con Indias (1700-1714)". La burguesía mercantil gaditana (1650-1868). Cádiz, 1976. 
guerras revolucionarias - con la consiguiente apertura de los puertos coloniales a los extranjeros-, la guerra de la Independencia española y la emancipación de los dominios americanos (6).

La explotación estadística de la información recogida y el asesoramiento de la bibliografía consultada (7) han dado como resultado el

(6) Vid. A. GARCIA-BAQUERO, Comercio colonial y guerras revolucionarias. La decadencia económica de Cádiz a raíz de la emancipación americana. Sevilla, 1972, p. 40 .

(7) Relación de la bibliografía consultada:

BALLESTEROS GAIBROIS, M.: "Sevilla y el comercio de Indias", en Cuadernos Historia 16, n.․ 152 .

BORREGO PLA, M.C.: "Tráfico comercial de España con Indias (1700-1714)". La burguesia mercantil gaditana (1650-1868). XXXI Congreso Luso-español para el progreso de las ciencias. Cádiz, 1976.

BUSTOS RODRIGUEZ, M.: Un comerciante saboyano en el Cádiz de Carlos II. (Las memorias de Raimundo de Lantery. 1673-1700). Cádiz, 1983.

COMELLAS GARCIA-LLERA, J.L.: "Dinámica y mentalidad de la burguesía gaditana en el siglo XVIII". La burguesía mercantil gaditana (1650-1868). Cádiz, 1976.

DOMINGUEZ ORTIZ, A.: "La burguesía gaditana y el comercio de Indias descde mediados del siglo XVII hasta el traslado de la Casa de Contratación". La burguesía mercantil gaditana (1650-1868). Cádiz, 1976.

FERNANDEZ MAYO, M.: "Correspondientes y comisionistas en el negocio americano a mediados del siglo XVIII". Cádiz en su bistoria. VI Jornadas de Historia de Cádiz. Cádiz, 1987.

GARCIA-BAQUERO GONZALEZ, A.: Comercio colonial y guerras revolucionarias. La decadencia económica de Cádiz a raíz de la emancipación americana. Sevilla, 1972.

GARCIA-BAQUERO GONZALEZ, A.: Cádiz y el Atlántico (1717-1778). (El comercio colonial español bajo el monopolio gaditano). Cádiz, 1988.

GARCIA-BAQUERO GONZALEZ, A.: Andalucia y la carrera de Indias (14921824). Sevilla, 1986.

MARTINEZ SHAW, C.: "Las relaciones económicas entre Cataluña y la Baja Andalucia en el siglo XVIII" en Actas I Congreso Historia de Andalucia, III, 1978, pp. 347-356.

MILLAN CHIVITE, J.L.: "Revolución política y crisis económica y urbana (17901868)", Cádiz en su Historia. I Jornadas de Historia de Cádiz. Cádiz, 1982.

MILLAN CHIVITE, J.L.: "Los comerciantes navarros en el Cádiz de los comerciantes (1740-1920)". Primer Congreso General de Historia de Navarra. Príncipe de Viana, Anejo 9 (1988).

MOLAS RIBALTA, P.: La burguesía mercantil en la España del Antiguo Régimen. Madrid, 1985.

NAVARRO GARCIA, L: "La Casa de Contratación en Cádiz". La burguesía mercantil gaditana (1650-1868). Cádiz, 1976.

RAMOS SANTANA, A.: La burguesia gaditana en la época isabelina. Cädiz, 1987.

RUIZ RIVERA, J.: El Consulado de Cádiz. Matrícula de comerciantes. 17301823. Cádiz, 1988.

SOLIS, R.: El Cádiz de las Cortes. La vida en la ciudad de 1810 a 1813. Madrid, 1987. 
análisis que presentamos a continuación. Se trata, como apuntábamos antes, de una modesta contribución al estudio del comercio gaditano, ya que sólo puede ser así por la parcialidad de las fuentes y por la limitación de las catas. No obstante, hemos podido extraer una serie de conclusiones, que si bien no aportan muchas novedades, sí ofrecen una semblanza global del tema estudiado y, sobre todo, como también señalábamos, muestran la riqueza de los fondos notariales y del tipo documental elegido para ahondar en el conocimiento de un aspecto tan importante y fundamental para el Cádiz de los siglos modernos y contemporáneos:

Comenzaremos por analizar el elemento personal de los poderes, es decir, otorgantes y apoderados, para pasar luego a conocer las diferentes actividades comerciales que desarrollaban mediante el estudio de los tipos de poderes. Tódo ello nos permitirá distinguir los circuitos comerciales y, en menor medida, por la parquedad de las fuentes en tal sentido, el volumen de las transacciones y las mercancías objeto del tráfico comercial.

\section{ESTUDIO ESTADISTICO-DESCRIPTIVO DE LOS PODERES NOTARIALES}

\section{II.1. Estudio del elemento personal: otorgantes y apoderados}

\section{II.1.1. Otorgantes}

Son los hombres de negocios del comercio gaditano. Pero no siempre se llamaron así. A través de los documentos consultados se percibe toda la evolución que el comercio y la condición de comerciante experimentaron a lo largo de los siglos modernos.

En 1650, por ejemplo, no encontramos comerciantes propiamente denominados. De los diecisiete casos recogidos, solamente en dos aparece el otorgante definido como mercader. Los restantes poderes, o bien no ofrecen dicha información, o bien nos hablan de capitanes de navío o contramaestres. $Y$ es que parece ser que por esta fecha "comerciantes y marinos se confundían muchas veces en la misma persona" (8). Esta idea viene constatada por las actividades que desarrollan estos señores y que se desprenden de los poderes recopilados.

(8) Cfr. J.L. COMELLAS: "Dinámica y mentalidad de la burguesía gaditana en el siglo XVIII". La burguesía mercantil gaditana. (1650-1868). Cádiz, 1976, pág. 20. 
En efecto, dichas actividades son las propias de un hombre de comercio e incluso encontramos a dos de ellos -presentados como capitanes de navío- perteneciendo a sendas casas comerciales (son los casos de Baltasar de Breña y de Juan Grande). Caro Baroja en La hora navarra del $X V I I$ señala también esa íntima relación entre capitanes y mercaderes de lonja, fruto de una época en la que no existía una clara distinción entre la marina de guerra y la marina mercante (9).

Insistiendo en este asunto de la terminologia, hemos de comentar igualmente el hecho de que se hable de mercader y no de comerciante. Ambos vocablos eran sinónimos en el siglo XVII, aunque, como apunta Pere Molas, la voz mercader gozaba de mayor tradición y prestigio (10). Con tal denominación se definía a "los que por mar o tierra hacen venir de cualquier género que sea para vender al por mayor o en grueso" (11). Por tanto, hacía referencia muy concretamente al comercio al por mayor, ocupación reconocida por los hombres de la época como muy honesta y honrosa, equiparable a las armas, las letras y la agricultura. Se distinguía así claramente el oficio de mercader del pequeño comerciante que vendía al por menor y que, en contrapartida, no gozaba del mismo respeto y admiración. Se restringía, pues, el concepto de comercio "al marítimo y de por grueso, porque el que vende por menudo no se puede decir verdaderamente mercader" (12).

Con el tiempo, comerciante y mercader -como hemos visto hasta ahora sinónimos- pasaron a designar distintas actividades económicas y diferentes condiciones sociales. La nueva palabra comerciante pasó a referirse a los mayoristas y el término mercader fue quedando arrinconado para designar a los tenderos o mercaderes de tienda abierta. El siguiente comentario del ilustrado Eugenio de Larruga, claramente beligerante contra los mercaderes al por menor, ejemplifica bastante bien esta circunstancia:

"A los que venden por menor en sus tiendas llama con toda propiedad nuestra lengua tenderos, aunque la urbanidad con capa de cortesía ha introducido llamar mercaderes". [Estos] "no pueden ni deben confundirse con los comerciantes" (13).

(9) Cit. in Ibídem, pág. 20.

(10) P. MOLAS: La burguesia mercantil en la España del Antiguo Régimen. Madrid, 1985, pág. 51.

(11) Ibídem, pág. 51.

(12) Definición que data de 1600, recogida por Pere Molas en su ya citado libro, p. 49.

(13) Ibídem, pág. 51. 
Esta distinción es totalmente clara en nuestra documentación a partir de 1750. De los ciento once poderes de estos años, ochenta y nueve califican al otorgante como hombre de comercio o comerciante, uno como maestre de navío, otro como sobrecargo y dos como propietarios de barcos; los diecisiete casos restantes carecen de dicha informaciôn. Ha desaparecido, por tanto, el vocablo mercader. Incluso diríamos que el cambio en la terminología se percibe ya en 1700 , puesto que en esta fecha tampoco se habla de mercaderes y sí de hombres de negocios y de seguradores de barcos (como actividades complementarias). En relación con esta última idea, hay que señalar la naturaleza diversa y a veces contrapuesta de las operaciones mercantiles en el Cádiz de estas fechas. Como dice García-Baquero, "una misma firma comercial actuaba unas veces como comerciante, otras como naviero, y otras como asegurador" (14).

En 1850 la característica más señalada, junto al brusco descenso del gran comercio, es la aparición en los poderes notariales consultados del pequeño comerciante de tienda que abastece el mercado local.

Muy vinculadas al gran comercio estaban las casas de negocios o compañías comerciales. El origen de estas sociedades mercantiles estaba motivado bien en la imposibilidad de alcanzar ciertos fines con el solo esfuerzo individual, bien en el deseo de obtener o ampliar un capital sin los inconvenientes del préstamo o del riesgo unipersonal (15). En Cádiz, dichas sociedades fueron especialmente numerosas en el siglo XVIII, edad dorada del comercio americano y, por extensión, del comercio español y europeo en general. Todos los estudiosos del tema coinciden en la anterior afirmación y así se desprende de nuestro pequeño sondeo a través de los poderes notariales: como puede verse en el Cuadro II, 1750 y 1800 son los años con mayor número de compañías comerciales, sobre todo el primero. Anteriormente, la presencia de estas casas de negocios es bastante baja en relación con los otorgantes individuales (16) y, por lo que respecta a 1850, el declive de la actividad comercial no sólo se plasma en la escasez de compañías sino en la escasez general de poderes de temática mercantil.

(14) A. GARCIA-BAQUERO: op. cit., pág. 47.

(15) Vid. A. GARCIA-BAQUERo: Cádiz y el Atlántico (1717-1778). Cádiz, 1988, p. 405.

(16) Hay que señalar que aunque en 1700 sólo hemos encontrado cinco poderes de temática comercial, uno de ellos está otorgado por varios individuos y compañías a la vez. 
Se ha escrito mucho sobre el papel desempeñado por los extranjeros en el comercio gaditano de los siglos modernos. Como apunta el profesor Comellas, Cádiz, en estas fechas, estaba poblado por españoles de todas las provincias y extranjeros de todas las naciones (17). El estudio que hacemos a continuación puede resultar ilustrativo al respecto. En rigor, podemos establecer solamente dos grandes grupos (ver cuadro III):

A. Un gran grupo, mayoritario con diferencia (representan el $84,2 \%$ del conjunto de poderes analizados), constituido por los vecinos de Cádiz. Sin embargo, hemos de hacer matizaciones porque dentro de este grupo encontramos numerosos nombres característicos de otras regiones españolas o de claro origen extranjero. No obstante, no se especifica en ningún momento dicho origen foráneo y no sabemos a qué atribuir esta omisión de las fuentes. Podríamos explicarlo como un afincamiento definitivo en tierras gaditanas, de manera que se obviaría la procedencia de tales individuos. De todas formas, nos inclinamos a pensar que se debe solamente a una costumbre de la notaría, puesto que existen otras que sí hacen constar la nacionalidad cuando se trata de extranjeros avecindados en la ciudad. Además, hemos localizado muchos de nuestros otorgantes en la Matrícula de Comerciantes publicada por Julián Ruiz Rivera (18) y en ella consta el origen extranjero de los mismos.

'En el Apéndice hemos insertado un censo por años de los otorgantes. En él hemos recogido todos los nombres, bien de individuos, bien de compañías, que aparecen en el conjunto de los ciento treinta y tres poderes analizados. Por lo tanto, no refleja el número real de poderes sino el número de otorgantes, ya que hemos suprimido los que se repiten y hemos especificado los que aparecen en poderes otorgados colectivamente (19).

(17) J.L. COMELLAS: op. cit., pág. 24.

(18) J. RUIZ RIVERA: El Consulado de Cádiz. Matrícula de comerciantes. 1730-1823. Cádiz, 1988.

(19) Los poderes otorgados colectivamente son cuatro: uno de 1700 (Not. 19, Leg. 4.443 , fol. 61) y tres de 1750 (N. 19, Leg. 4.480, fols. 4, 326, 1.636). Otras dos advertencias: en primer lugar, que en dicha relación nos hemos limitado a transcribir los nombres de los otorgantes tal como aparecían éscritos en los documentos, sin intentar corregir su grafía; en segundo lugar, que hay una serie de casos en los que se repiten los mismos otorgantes, debiéndose ello a que figuran en la documentación tanto a nivel particular como formando parte de sociedades o compañias comerciales. 
Este censo nos puede servir para contabilizar de alguna manera la presencia en Cádiz de comerciantes extranjeros. Como puede observarse, la curva ascendente comienza en 1700 -pues en 1650 sólo dos de los dieciséis otorgantes nos parece que reúnen dicha característica: Bartolomé Deecón y Claudio Salive- y llega al punto máximo en 1750, con más de treinta otorgantes extranjeros. En 1800, el número de ellos continúa siendo muy elevado -unos veinte aproximadamente-, aunque ya ha bajado un poco con respecto a la fecha anterior. Y en 1850 la desaparición del elemento foráneo ha sido rotunda: sólo dos otorgantes, representantes ambos de compañias comerciales, pueden considerarse extranjeros: Enrique Napp y Bernardo Molet (en este caso, podría tratarse también de un nombre del área catalano-levantina). En relación con este último comerciante, hay que constatar la presencia de familias extranjeras durante varias generaciones: hemos encontrado dos casos, uno, el de los Lynch, que nos aparecen en 1750 -Diego y Tomas Lynch- y en 1800 -Tomas y Enrique Lynch-, y otro, el de los Mollet, que aparecen en 1750 y en 1850 -en esta ocasión con el apellido castellanizado: Molet.

Si aventurado ha sido contabilizar el número de extranjeros solamente por la grafía de sus nombres, más atrevido aún podría resultar intentar averiguar sus nacionalidades. Por ello, nos limitaremos a hablar de una presencia notable de italianos y franceses, y de una presencia menor, aunque importante, de comerciantes procedentes de otros países europeos, fundamentalmente británicos, holandeses y alemanes.

Pero, como decíamos al principio, Cádiz no sólo estaba poblado de extranjeros. También venían a nuestra ciudad numerosos inmigrantes de otras provincias españolas (20). En este caso, determinar el origen de los otorgantes por medio de sus apellidos nos resulta aún más inseguro que en el caso de los extranjeros. Por ello, aunque pudiera resultar indicativo, no vamos a realizar dicha aproximación, ya que los resultados podrían ser bastante engañosos. Lo que no nos cabe duda es de la presencia en Cádiz de gran número de españoles procedentes de otras regiones. En efecto, debieron establecerse en la ciudad gentes de las más diversas procedencias, predominando, como señalan los especialistas en el tema, los avecindados de origen cantábrico, vasconavarro o catalano-levantino. En nuestra documentación encontramos

(20) Interesante al respecto es el estudio de Julián RUIZ RIVERA, en su obra ya citada, sobre la emigración peninsular a Cádiz. 
apellidos como Arteaga y Verovia, Iribarren, Urrutia o Mendiburu, de clara procedencia vasconavarra, y otros, como Campíns, Comín, Casal o Font y Carbonell, de indudable raigambre catalana.

B. Un segundo grupo, que representa el $16,8 \%$ restante, lo componen aquellos otorgantes que tienen otra vecindad o nacionalidad y residen temporalmente en Cádiz. Son veintiuno los casos contabilizados y se reparten de manera regular entre todos los años revisados, con la clara excepción de 1650. En este año se localizan ocho de los poderes de otorgantes residentes en Cádiz y todos ellos salvo uno -natural de Lima- son vecinos de Sevilla, especificándose incluso la colación a la que pertenecen. Este hecho debe estar en relación con el proceso de decadencia que experimentó Sevilla a lo largo del XVII. Como es sabido, el deterioro de la navegabilidad del Guadalquivir, la mejor situación de Cádiz en la nueva coyuntura y, sobre todo, el hecho de que el puerto gaditano era ya, reconocidamente o no, la llave del tráfico con Indias se unieron para conseguir finalmente el traslado del monopolio del comercio indiano de Sevilla a Cádiz. En 1650 esta situación era ya bastante palpable, sobre todo tras la gran epidemia de 1649, que supuso para la ciudad del Guadalquivir una gran catástrofe en todos los sentidos. La elevada presencia de sevillanos entre los poderes de 1650 corrobora todas estas ideas.

\section{II.1.2. Apoderados}

El estudio de este grupo no ha dado tantos frutos como el de los otorgantes. El motivo radica en la diversidad de la información recogida, variedad que dificulta y casi impide la cuantificación homogénea de la misma. Por ejemplo, analizar estadísticamente los lugares de vecindad o residencia de los apoderados carece de sentido ya que éstos son tan diversos como diferentes los circuitos comerciales. Esto se debe a que normalmente se otorga el poder a una persona que reside en el lugar donde se ha de realizar el encargo. Por ello creemos que la primera característica a examinar es la distinción entre los que viajan y los que no viajan:

-Los que viajan son un grupo bastante reducido: sólo doce de los ciento treinta y tres reseñados, lo que representa el 9\% del conjunto de poderes. Son especialmente numerosos en 1650 , pues la mitad de los apoderados que viajan se concentran en este año. Todos ellos se trasladan a las Indias, lo cual explica en cierta manera el hecho de 
los viajes: es de suponer que por estas fechas la infraestructura del tráfico comercial con las colonias no estaría aún debidamente organizada, por lo que las compañías o comerciantes particulares se verían obligados a mandar sus delegados hasta allí para realizar las distintas operaciones mercantiles. Con el tiempo, la infraestructura comercial se iría haciendo más compleja y sofisticada y los hombres de negocios tendrían sus propios delegados o comisionistas en las ciudades que eran centro de sus actividades comerciales.

Esto es, al menos, lo que se desprende de la documentación consultada, ya que a partir de 1700 los poderes en los que el apoderado se desplaza disminuyen notablemente. De los seis protocolos restantes, uno pertenece a 1700 , cuatro a 1750 y uno a 1800 . En tres de ellos se sigue viajando a América y en los otros tres se viaja a diferentes lugares de España: a Madrid, a Santa Cruz de Tenerife -en ambos casos, para cobrar deudas-y al Norte -para comprar mercaderías-.

- Los ciento veintiún apoderados restantes no viajan. En este grupo, sin embargo, hemos de hacer otra división: por un lado, aquellos representantes que tienen su domicilio en Cádiz y cuya tarea ha de llevarse a cabo en la misma ciudad, y por otro, aquellos que tienen su residencia en cualquier otra ciudad de España, Europa o América y cuya misión a cumplir ha de efectuarse en ese mismo lugar u en otro cercano. El primer grupo es minoritario -14 poderes- y siempre coincide con viajes de los otorgantes. Es decir, es el otorgante el que se traslada y deja en Cádiz un apoderado que se encargue de administrar sus negocios y de realizar las operaciones mercantiles y financieras que considere oportuno. El segundo caso representa la tónica general, puesto que constituye el $80,5 \%$ del conjunto de poderes.

En segundo lugar llamaríamos la atención sobre la variabilidad del número de apoderados por poder. Lo habitual es que el poder se otorgue a una sola persona, hecho que se confirma por el elevado número de documentos en que se da tal circunstancia (en noventa casos de los ciento treinta y tres). Sin embargo, existe un porcentaje considerable de poderes en los que el poder se otorga bien a dos personas $(18 \%$ de los casos), bien a tres $(8,2 \%)$, bien a cuatro $(4,5 \%)$ o bien a cinco $(1,5 \%)$. Cuando se concede un poder a más de una persona suele coincidir con un encargo a realizar en las Indias, salvo algún caso aislado en el que el asunto otorgado tiene como lugar de 
ejecución alguna ciudad española (21). Por ello pensamos que el número de apoderados estaba directamente relacionado con los negocios americanos, buscando la explicación en la notable distancia que separaba la Península del continente americano. Nombrar más de un apoderado (22) significaba cubrirse las espaldas por si ocurría alguna complicación imprevista y, por lo tanto, asegurar al máximo la realización de la operación requerida.

Por último, nos interesa conocer la procedencia profesional de estos individuos. Casi en la mitad de los casos (49,6\%) no consta dicha información, mientras que en un porcentaje elevado (34,5\%) se especifica que se trata de hombres de comercio o de compañias comerciales. El 15,9\% restante se distribuye de la siguiente manera: once casos en los que el poder se concede a un procurador -son fundamentalmente los poderes para pleitos-, cinco casos en los que el apoderado es un marino (capitán, sobrecargo, piloto u oficial de navío), dos casos en los que el poder se otorga a un eclesiástico (23), un caso en el que el representante es el Contador Mayor del Tribunal de la ciudad de Lima, un caso en que se trata de un escribano y, por último, un caso en el que se otorga el poder a un militar (ver cuadro V).

La escasa información sobre este aspecto en la mitad de los poderes examinados nos induce a pensar bien que otorgantes y notarios no concedían mayor importancia a tal referencia, bien que no se hacía constar porque lo normal era que se tratara de comisionistas o delegados testaferros que tenían como profesión habitual dicha ocupación. Nos inclinamos por esta última hipótesis, que nos parece más lógica, pues muchos de los apoderados -con domicilio en distintas ciudades de América- se repiten constantemente a lo largo de la documentación consultada.

(21) Se trata de un poder para pleitos otorgado en 1800 por Joaquín Pedro Hinrichsen y Juan Francisco Bradamonde, hombres del comercio de Cádiz, a seis procuradores, dos residentes en Cádiz, dos en Sevilla y los dos restantes en Madrid. (N. 19, Leg. 4.557, fol. 3.081).

(22) Cuando se nombra más de un apoderado siempre se hace constar una jerarquía entre ellos. Es decir, se especifica que el segundo sólo entrará en acción si el primero sufre algún contratiempo - enfermedad, muerte o incapacidad de algún tipo-; el tercero, si le sucede algo al segundo, y así sucesivamente.

(23) Se trata de dos poderes de 1650 para cobrar determinadas cantidades en Vejer y Baena respectivamente (N. 19, Leg. 4.405, fols. 501 y 593). 


\section{II.2. Estudio de las actividades comerciales a través de los tipos de poderes}

El análisis de los tipos de poderes puede resultarnos uno de los apartados más interesantes, puesto que nos va a permitir conocer las distintas operaciones y actividades que desarrollaban los comerciantes gaditanos.

Establecer una tipología más o menos coherente y explicativa nos ha resultado algo complicado, ya que existe una gran variedad de poderes, no siempre fácilmente agrupables en categorías similares. Finalmente, hemos establecido cinco grandes grupos: cuatro de ellos relacionados directamente con actividades comerciales y el quinto restante de actividades no mercantiles pero cuyos otorgantes eran hombres de negocios. Veámoslos detalladamente:

\section{Cobros}

En este grupo hemos incluido todos los poderes que se otorgan con la finalidad de cobrar una cantidad adeudada, bien sea en metálico o en mercancías, como consecuencia de una previa venta comercial. Constituye el grupo mayoritario con diferencia, pues representa casi el $50 \%(47,4)$ de los poderes recogidos.

Ofrece dos variantes que hemos dado en llamar general y especial:

General, cuando se otorga el poder para cobrar en determinada ciudad o región todas las cantidades adeudadas de todas las personas que las deban satisfacer (24).

Especial, cuando se otorga el poder para cobrar una cantidad, concreta o general, de una o varias personas determinadas. En estos casos se especifica los nombres de dichas personas o entidades, su domicilio, la cantidad adeudada -aunque no siempre, porque a veces se habla en general de "todas las cantidades adeudadas"- y el origen de la deuda, es decir, se hace constar el producto intercambiado o

(24) A continuación transcribimos, a modo ilustrativo, un poder para cobrar de carácter general: "para que en mi nombre, en cualquiera partes de las Indias, pida, demande, reciba y cobre todas las partidas de maravedises, reales, ducados, pesos de oro y plata, mercadurias, esclavos, ganados y otros frutos de la tierra, de cualquier calidad y cantidad que sea, que basta el dia de boy se me deben y pertenecen en virtud de contratos püblicos, cuentas corrientes y fenecidas, cédulas $y$ libranzas, cartas, misicas y dé crédito, partidas, libros de registros, poderes, cesiones..." (N. 19, Leg. 4.405, fol. 438). 
bien si se trata del cobro de una letra de cambio, aunque también es habitual que se hable de mercaderías en general (25).

A veces ocurre que se otorgan poderes que reúnen las dos variantes de general y especial, pero son casos aislados. Lo más usual es el poder para cobrar de carácter general -34 casos-, aunque el poder especial también es bastante frecuente -25-.

\section{Nombramiento de representante/administrador}

Hemos incluido en este grupo una gran variedad de poderes que tienen siempre como nota común el nombramiento de una persona que se encargue de administrar determinados asuntos o bien que represente a su otorgante en determinadas situaciones, tratándose siempre de actividades relacionadas con la labor comercial. Este apartado comprende el $20 \%$ del conjunto de los poderes, convirtiéndose, pues, en el segundo grupo mayoritario.

-Lo más habitual es que el comerciante otorgue el poder para que el apoderado se haga cargo, en el lugar requerido, de las mercancías consignadas a su nombre, siempre con la finalidad posterior de hacerlas llegar a los distintos compradores. Casi el 30\% de los poderes de este grupo reúnen estas características.

- Una variante de la modalidad anterior consiste en otorgar el poder para que el delegado pueda embarcar mercancías a nombre del otorgante, bien con un rumbo prefijado, bien con el que considere conveniente. Sólo dos poderes se incluyen en este subgrupo.

- Y una tercera variante, de la que tenemos recogidos tres casos, estriba en otorgar un poder para recuperar mercancías consignadas por el otorgante de un barco que ha sido detenido, asaltado o bien que ha naufragado.

-Otro tipo de poder que hemos incluido en esta división es el que nombra un administrador para que se encargue de llevar un negocio (un caso), o para que se ocupe de despachar y fletar un navío (tres).

- Incluimos también en este grupo un poder expresamente otorgado para facultar a un compañero de negocios la posibilidad de tomar empréstitos.

(25) Igualmente, transcribimos un poder para cobrar de carácter especial: "para que en mi nombre cobre de Antonio Linares, vecino de Málaga, 2.942 reales y 15 mrs. de plata por el valor principal de una letra de cambio de 250 ducados, sacada por el susodicho el 20 de junio de 1744 sobre Carlos Metealge, de Hamburgo, a 90 dias, sba. a favor de mi apoderado, quien la endosó a favor mío y de mi compañia" 
-Más indirectamente relacionados con la actividad comercial propiamente dicha están cinco documentos en los que se otorga un poder a una persona para que represente al otorgante en una comisión de quiebra en la que está interesado. Una variante de este tipo se produce cuando el apoderado es encargado de asistir a una cesión de bienes (un caso).

-En penúltimo lugar, tenemos los poderes que nombran un representante para resolver cuestiones relacionadas con seguros de barcos (dos casos).

-Y finalmente, tenemos recogidos otros dos casos en los que únicamente se pide a los apoderados "cumplir las instrucciones que en adelante les vayan dando". Los hemos incluido en este amplio apartado porque suponemos que se trataría de instrucciones relacionadas con actividades mercantiles y que los otorgantes en cuestión serían celosos guardianes de su intimidad profesional.

\section{3. ${ }^{\circ}$ Actividades financieras}

Hemos agrupado con este nombre aquellas actividades que suponen una inversión financiera y un trasiego exclusivo de dinero, en ningún momento de mercancías. Encontramos tres tipos:

\section{- Cobros de préstamos}

En estos casos deducimos que se trata de un préstamo y no del cobro de una previa venta de mercancías porque en ningún momento se habla de ellas -y siempre se hace, aunque sea de forma genérica-. No obstante, hay veces en las que se especifica explícitamente (26).

El préstamo parece ser una de las actividades más habituales del comerciante gaditano, pues constituye, con doce casos, el $75 \%$ del conjunto de poderes incluidos en esta división.

\section{- Cobros de riesgos maritimos}

No podemos decir lo mismo de la actividad aseguradora, aunque bien es cierto que los seguros marítimos fueron muy importantes en el

(26) Insertamos también un ejemplo de poder para cobrar un préstamo: "para que en mi nombre cobre de José Miranda y Dominguez, vecino de Cartagena de Indias, 2.950 pesos dobles que le dejé en confianza..." (N. 19, Leg. 4.480, fol. 1.085). Como puede verse, no se habla para nada de mercaderías, motivo por el que hemos decidido incluirlo en el grupo de actividades financieras. De todas formas, como ya hemos señalado, hay otros casos en los que sí se habla expresamente de dinero prestado. 
entramado económico de estos siglos. Ramón Solís (27) habla de la realización de seguros como uno de los tipos de negocio claramente diferenciado dentro del marasmo de actividades que abarcaban, por entonces, las casas comerciales. García-Baquero recoge esta idea (28) y señala el elevado número de casas aseguradoras -especializadas en los seguros de riesgos marítimos- que existían en Cádiz en 1795.

Por ello, creemos que la escasez de poderes relacionados con esta actividad -sólo dos casos a los que habría que añadir otros dos que incluimos en el epígrafe anterior- podría deberse simplemente a una situación coyuntural o bien a que esta notaría no fuera muy requerida para este tipo de documentos.

\section{-Inversión de capital}

Tan sólo tenemos un caso pero es bastante ilustrativo (29). Se trata de un poder de 1800 otorgado por Sebastián Martín, vecino y del comercio de Cádiz, a Diego Juglai, residente en Madrid, para que cobrase de Carlos Bertazony, tesorero del Real Canal de Manzanares, las cantidades que debía percibir como accionista -con 20.000 reales de vellón- de una Compaña de diligencias que hacian el recorrido Madrid-Bayona.

\section{4.o Liquidaciones}

Los poderes incluidos en este apartado tienen como finalidad el arreglo de cuentas entre dos comerciantes o compañías de negocios (30). Esta modalidad aparece tardíamente, en 1800 . Y no se trata, como pudiera pensarse, de una simple transformación de las fórmulas notariales, ya que hemos comparado detenidamente toda la tipología de poderes y el que más podría parecérsele -el de cobros- continúa utilizándose, con ligeras transformaciones, en el mismo año de 1800.

Presenta también las dos variantes que contempla el poder para cobrar. Es decir, existe un poder para arreglar cuentas de carácter

(27) R. SOLIS, El Cádiz de las Cortes. Madrid, 1987, pp. 102-104.

(28) A. GARCIA-BAQUERO, Comercio colonial y..., pp. 47-48.

(29) Notaría 19, Leg. 4.555, fol. 767.

(30) De nuevo transcribimos, a título ilustrativo, un poder incluido en este grupo: "para que ajusten, liquiden y salden las cuentas que tengo pendientes con los señores Don Juan Campe y Compañia, del comercio de Madrid, relativas a los negocios y dependencias que entre nosotros ban intervenido, baciéndoles cargos, admitiendo justas datas, adiccionando partidas, reclamando y recaudando cuanto a mi favor resulte..." (N. 19, Leg. 4.555, fol. 77). 
general -cuando no se especifica la persona o compañía receptora- y existe un poder para arreglar cuentas de carácter especial -cuando sí se especifica-.

Los poderes para liquidar representan el último grupo en importancia, tras los poderes de carácter financiero y los poderes relacionados con actividades no comerciales, que:comparten la misma posición en el conjunto de la tipología estudiada.

\section{5.- Actividades no comerciales}

Hemos englobado en este capítulo una gran variedad de poderes que tienen como nota común su referencia a actividades de carácter no comercial. Los más comunes son para pleitos (el 50\% de todos los encontrados), mientras que el $50 \%$ restante se distribuye de la siguiente manera: dos poderes para administrar fincas, dos para asistir a los Reales Consejos y hacer una petición -que nunca se especifica-, cuatro para cuestiones de herencia -bien para dividir una, bien para aceptar otra, o bien para nombrar un albacea-administrador- $y$, finalmente, uno para comprar una finca perteneciente a patronato.

No hay que olvidar que todos estos poderes, aunque no tienen ninguna relación con la actividad mercantil, sí han sido otorgados por comerciantes. De todos ellos, quizás los que más nos interesen sean los referentes a administración y compra de fincas -tanto urbanas como rústicas-, ya que ilustran la tendencia de la burguesía mercantil a invertir sus ganancias en bienes inmuebles -especialmente tierras-como búsqueda de un mayor reconocimiento social y, en muchos casos, como paso previo al ennoblecimiento.

\section{II.3. Circuitos comerciales y mercancías intercambiadas}

El estudio de los espacios geoeconómicos en los que se desarrolla el comercio gaditano de este período es bastante factible con la información que nos ofrecen los poderes notariales, ya que siempre recogen el lugar donde el apoderado ha de llevar a cabo la tarea encomendada. Estos espacios comerciales son fundamentalmente tres: América, Europa y la Península junto con las Islas Canarias. No obstante, en los cuadros que hemos confeccionado, a los que de paso remitimos para la mejor comprensión de este capítulo (Vid. cuadros VI y VII), hemos contemplado un cuarto grupo al que llamamos genéricamente Europa y América. En este cuarto grupo incluimos todos los poderes en los que se da a entender que el circuito comercial abarca ambas zonas. Nuestro análisis va a consistir en determinar 
la importancia de cada una de estas áreas en las distintas catas realizadas y asimismo en ofrecer una visión de conjunto de los dos siglos estudiados.

Como puede observarse en los cuadros, en 1650 casi todo el comercio gaditano está orientado hacia las Indias. Los lugares donde se centra este comercio son bastante variados, aunque se nota un predominio de la provincia de Tierra Firme (con cuatro poderes para comerciar en ella) y, en menor medida, de La Habana. También existe algún tráfico comercial con la Península, concretamente con lugares cercanos a la ciudad como Sanlúcar, Sevilla, Vejer y Baena (Córdoba). En cuanto al comercio con Europa, es totalmente inexistente.

En 1700 , por el contrario, no encontramos comercio con las Indias y sí con Europa. Insistimos en que este año nos parece un tanto atípico en el conjunto de la documentación. Ya comentamos que nos llamaba la atención el escaso número de poderes que habíamos encontrado en dicho año y que creíamos que se debía a la escasa demanda de la notaría en aquel momento. En cualquier caso, la realidad es que, de los cinco poderes recogidos, uno hace referencia a un intercambio con la ciudad de Liorna, tres a comercio intrapeninsular -Madrid, Coruña y la propia ciudad de Cádiz- y en un caso no se hace saber.

1750 representa el gran apogeo del comercio con América: la mitad de los poderes de este año se conceden para asuntos relacionados con el comercio indiano. Ello es perfectamente comprensible si tenemos en cuenta que desde 1717 la Casa de la Contratación tenía su sede en Cádiz y que todo el comercio ultramarino de España y Europa se hacía desde nuestra ciudad. Además, las ciudades ejes de este comercio han ampliado considerablemente su espectro y abarcan prácticamente todo el continente: México, Buenos Aires, Cartagena de Indias, Veracruz, Lima, Santiago, Panamá, Portobello, etc. No obstante, los principales lugares de este comercio son, por este orden, Buenos Aires, Cartagena, Lima y el Reino de Nueva España en general.

Pero al mismo tiempo que se produce este gran auge del comercio americano -y, precisamente, al calor del mismo- se van a desarrollar considerablemente las relaciones comerciales con distintas zonas europeas. La mención en los poderes correspondientes a este año de ciudades como Hamburgo, Amsterdam, Liorna, París, Londres, Amberes, Dublin, Faro o Gibraltar es muestra fehaciente de este notable ascenso del comercio con Europa. No hay que olvidar, en este sentido, la importancia que tuvieron las mercancías europeas en el conjunto de las exportaciones españolas hacia América. 
Las actividades mercantiles también aumentan en este año en su vertiente peninsular, suponemos que, igualmente, influenciadas por el auge del comercio americano. Destacan, sobre todo, los intercambios con Sevilla y las Canarias, por lo tanto, muy vinculados también al tráfico indiano. Asimismo, encontramos un radio de intercambios próximo a Cádiz, que incluye la propia ciudad y otras como Sanlúcar, El Puerto de Santa María o Málaga. Más alejados de Cádiz tenemos a Valencia y Gandía en la costa levantina y el "Norte" -denominado de esta forma genérica- en la costa cantábrica. Por último, en el interior, solamente se constatan relaciones comerciales con Madrid.

En 1800 continúa el predominio del comercio con América y desciende con Europa, manteniéndose con el mismo porcentaje de 1750 los intercambios con otras regiones españolas. De todas formas, aunque el comercio indiano siga a la bandera, hay que reconocer que ha menguado notablemente respecto a la fecha anterior, ya que puede decirse que se ha reducido prácticamente a la mitad. Esto es lógico si tenemos en cuenta que a partir de 1797 ya es perceptible el proceso de decadencia que se apoderará de la ciudad a lo largo del siglo XIX. Con todo, las ciudades de América con las que comercia Cádiz siguen siendo tan variadas como en 1750 , e incluso hay que destacar la aparición de Estados Unidos (Nueva York, Charleston y Filadelfia) en este panorama geocomercial.

El comercio con Europa desciende bastante respecto a la fecha anterior. Ello resulta igualmente lógico si pensamos que en ese momento se están desarrollando las guerras revolucionarias y que, aparte de los entorpecimientos de carácter general que provocarían, España puso serias trabas al comercio con Inglaterra o con Francia en aquellos periodos en que se hallaron enfrentadas. En concordancia con este hecho resulta sintomático que no aparezca Londres -en 1750 muy presente- entre las ciudades europeas relacionadas comercialmente con Cádiz.

En cuanto al intercambio dentro de nuestras fronteras, hay que decir que permanece en los mismos niveles de 1750. El espectro de ciudades permanece también más o menos igual al de dicha fecha: prácticamente todo el comercio se realiza con ciudades periféricas como: Barcelona, Alicante, Málaga, Sanlúcar, Lisboa, Pasajes o San Sebastián, y muy poco con el interior (Sevilla y Madrid).

En 1850 ha disminuido ya considerablemente el comercio gaditano. Con América casi ha desaparecido y con Europa queda una muestra simbólica. También ha descendido notablemente con otras zonas de España, consecuencia, suponemos, del declive general. Lo más 
característico de este año, ya lo decíamos, es la aparición de la figura del pequeño comerciante. En concreto, se trata de un poder por el que el dueño de una tienda de zapatos nombra un apoderado para que administre y gobierne su negocio durante su ausencia de la ciudad -de la que no ofrece razones-. Este documento notarial puede servir de botón de muestra de una nueva realidad: la desaparición del gran comercio ultramarino y el auge del pequeño comerciante de tienda abierta, tan característico de la ciudad durante los dos últimos siglos.

En conjunto, pues, tenemos que el comercio gaditano está dirigido principalmente, y si exceptuamos el caso atípico de 1700 y el lógico de 1850, hacia América: casi la mitad de todos los poderes (49\%) tienen como punto de llegada ese continente. El comercio con otros lugares de España ocupa el segundo lugar con el 31\% de los poderes. $\mathrm{Y}$ en tercer lugar aparece el comercio con Europa (14,5\%). Por último, tenemos el grupo de actividades comerciales realizadas conjuntamente con América y Europa, que cuenta solamente con siete casos de todos los analizados.

Por su parte, los circuitos comerciales son tremendamente variados. Como hemos visto, todo el continente americano está presente en las transacciones comerciales gaditanas, sobre todo a partir de 1800 con la incorporación del mercado estadounidense. También en Europa la cobertura comercial es bastante amplia, destacando una mayor presencia de la zona Norte (puertos alemanes, británicos y flamencos) sobre la Mediterránea (Liorna y Génova fundamentalmente). En la Península, los intercambios comerciales se realizan básicamente con las regiones periféricas (tanto atlántica, como cantábrica y mediterránea), mientras que son notablemente escasos los contactos con el interior, exceptuando, no obstante, el caso de Madrid.

En contrapartida con el volumen de información que ofrecían los poderes para el estudio de los circuitos comerciales, nos encontramos con un tremendo vacío en el tema de los productos intercambiados. Un estudio de los mismos a través de los poderes notariales ha de resultar necesariamente incompleto e inconsistente. El motivo radica en la parquedad de las fuentes en tal sentido, pues casi siempre se refieren a ellos en sentido genérico, sin individualizar el producto concreto que se compra o se vende. 
La fórmula más habitual en las primeras catas es la siguiente:

"otorgo este poder... para que en mi nombre y como más convenga pida, demande, reciba y cobre todas las partidas de maravedíes, reales, ducados, pesos, barras de oro y plata, mercadurías, esclavos, ganados, frutos de la tierra, bienes raíces y muebles, semobientes y demás cosas que se me deban y pertenezcan en virtud de..." (31).

No obstante, existen diversas variantes sobre este mismo formato. Así, en otros casos, tras la frase "todas las partidas de maravedíes, reales, ducados, pesos, barras de oro y plata, mercadurías" aparece "añil, cochinilla, zarzaparrilla y otros productos de la tierra" (32) o bien "añil, cochinilla, zarzaparrilla, esclavos, ganados, pan, trigo, cebada y otros frutos de la tierra" (33).

Todos los ejemplos anteriores son de 1650. Desconocemos si las variaciones responden a cambios reales en las mercancías. En todo caso, es evidente que todas ellas eran objeto de intercambio comercial.

A partir de 1750 se continúa hablando genéricamente de mercaderías, pero la fórmula se ha simplificado notablemente. Unas veces se habla de "todas las cantidades de dineros, frutos, mercaderías y otras cosas..." (34), otras de "todos los efectos, géneros y mercaderías" (35), e incluso se reduce a "todo lo que nos deben" (36).

En resumen, el empleo de la forma genérica es lo más usual en el conjunto de poderes. Muestra de ello es que sólo en quince casos aparece explicitado el producto de la transacción comercial: en dos ocasiones se habla de cacao, de tabaco y de sempiternas y con una sola mención aparecen: almendras, vinos, granas, hilos, alfileres, libros, bretañas, escarlatas y un carruaje.

Por lo tanto, y según se desprende de la escasa información con que contamos, el cuadro de las mercancías intercambiadas en el Cádiz de los siglos modernos se estructuraría más o menos de la siguiente manera: por un lado, un comercio de exportación que tendría como dirección prioritaria el mercado americano. En este comercio se incluirían exportaciones de productos españoles y exportaciones de mer-

(31) N. 19, Leg. 4.405, fol. 144.

(32) N. 19, Leg. 4.405, fol. 166.

(33) N. 19, Leg. 4.405, fol. 501.

(34) N. 19, Leg, 4.480, fol. 294.

(35) N. 19, Leg. 4.480, fol. 842.

(36) N. 19, Leg. 4.480, fol. 1.263. 
cancías extranjeras -en muchos casos, según García-Baquero (37), muy superiores a las primeras-. Entre las exportaciones de productos españoles ocuparían un lugar preferente los derivados de la agricultura y la ganadería. En este sentido, recordemos los ejemplos anteriores en los que se hablaba constantemente de "semobientes (sic), ganados y otros frutos de la tierra", así como la exportación de vinos y de almendras ya citada. Por el contrario, la exportación de mercancías extranjeras se centraría sobre todo en productos manufacturados, teniendo un capítulo muy destacado los procedentes de la industria textil en general. En nuestros poderes tenemos una muestra simbólica de ellos: sempiternas, compradas en Londres; escarlatas y de nuevo sempiternas, también compradas en Inglaterra; y, por último, bretañas, compradas en Málaga a una Compañía de comerciantes franceses.

Por otro lado, un comercio de importación de productos coloniales que, a su vez, serían exportados desde Cádiz a otros lugares de España y Europa. Estas importaciones se compondrían fundamentalmente de materias primas derivadas de la agricultura, ganadería y minería americanas, sin olvidar, evidentemente, las importantes remesas de caudales. Los ejemplos reseñados al comienzo de este apartado ilustran estas importaciones: añil, cochinilla, zarzaparrilla, ganados, barras de oro y plata, etc. También fueron muy importantes, sobre todo en el siglo XVIII, las importaciones de tabaco y cacao, de lo que también tenemos constancia por las fuentes analizadas.

Para terminar este breve estudio de las mercancías haría falta conocer el volumen de los intercambios comerciales. Sin embargo, no es posible por la comentada parquedad de los poderes al respecto. Además, los contados casos en los que se señalan las cantidades comercializadas recogen tal variedad de monedas que dificulta aún más el tratamiento del tema. De todas formas, el análisis de ese escaso número de poderes no sería en absoluto representativo del conjunto de las transacciones.

\section{CONCLUSIONES}

Aunque pudiera parecer que la muestra recogida es demasiado corta, sin embargo, creemos que permite obtener conclusiones válidas, puesto que coinciden, en general, con los resultados obtenidos por otras investigaciones más completas y de mayor envergadura.

(37) A. GARCIA-BAQUERO, Comercio colonial y..., pp. 55-61. 
La primera conclusión es la confirmación de una evidencia: prácticamente casi todo el comercio gaditano se encuentra enfocado hacia el mercado colonial. En función de este hecho se articula todo el entramado mercantil de la ciudad, desde los propios hombres del comercio hasta los productos intercambiados, pasando por las actividades que desarrollan y la importancia de determinadas rutas comerciales.

En cuanto a los hombres de negocios, resulta también evidente que no son gaditanos los artífices del encumbramiento comercial de la ciudad. Como vimos, en la primera mitad del siglo XVII la presencia de vecinos de la ciudad y de sevillanos era superior a la presencia foránea. Sin embargo, cincuenta años más tarde el número de extranjeros había superado con creces a los nativos de Cádiz, y no digamos ya en 1750 y 1800. Además, a este elevado número de extranjeros hay que añadir la masiva llegada de españoles procedentes de otras provincias, fundamentalmente cántabros, vasconavarros y catalano-levantinos.

Pero al calor del comercio colonial no sólo llegaron numerosos extranjeros; también existió una extensa red de sociedades mercantiles que controlaban -en muchos casos desde fuera de nuestras fronterastodo el tráfico ultramarino. Las actividades desarrolladas por estas casas comerciales, y por los propios comerciantes particulares, eran muy variadas. En efecto, no era frecuente el comerciante especializado en un determinado tipo de negocio, de manera que abarcaba todo o casi todo, actuando tanto como comerciante, como prestamista, naviero o asegurador.

Por otra parte, los poderes que no hacen referencia a actividades comerciales de sus otorgantes, nos muestran a una burguesía mercantil -ya a finales del XVIII- que invierte en fincas urbanas y que compra tierras, lo cual, evidentemente, está en relación con el proceso de ennoblecimiento de comerciantes ricos que apuntan distintos estudiosos del tema (38).

Por lo que respecta a las áreas en que se desarrolla el comercio gaditano, hay que volver a señalar el predominio absoluto, durante todo el período, del circuito americano. El tráfico con Europa y con la propia Península está en gran medida mediatizado por el comercio colonial. Se exportan productos españoles y extranjeros hacia América y se importan gran número de materias primas coloniales para, una vez en Cádiz, exportarlas al resto de España y a Europa. Con esta últi-

(38) P. MOLAS en su obra ya citada recoge las impresiones de distintos investigadores sobre este tema, pp. 148-149. Por su parte, A. RAMOS en su estudio sobre La burguesía gaditana en la época isabelina constata igualmente dicha realidad. 
ma se comercia sobre todo con los puertos norteños y, en menor medida, con los mediterráneos. Dentro de nuestras fronteras, las relaciones comerciales son especialmente intensas con todo el litoral, exceptuando los casos excepcionales de Madrid y Sevilla en el interior.

Por último, hay que poner de relieve la importancia del siglo XVIII en el conjunto del período estudiado. De todos es conocido lo que supone esta centuria para el comercio gaditano. Este hecho es confirmado por nuestra documentación, en la que se percibe claramente tres momentos distintos: la fase de ascenso de la segunda mitad del XVII, el crecimiento sostenido de todo el XVIII, y el brusco y rotundo descenso de la primera mitad del XIX.

\section{CUADRO I \\ CLASIFICACION DE LOS OTORGANTES SEGUN SUS PROFESIONES}

PROFESION

\begin{tabular}{llr}
\hline Año 1650 & Capitán & 5 \\
& Mercader & 2 \\
& N/C & 10 \\
& Subtotal & 17 \\
\hline \multirow{2}{*}{ Año 1700} & Hombre de Negocios & 2 \\
& Hombre de Neg./Aseg. & 2 \\
& N/C & 1 \\
& Subtotal & 5 \\
\hline \multirow{2}{*}{ Año 1750} & Comerciante & 39 \\
& Maestre de Navío & 1 \\
& Sobrecargo & 1 \\
& Dueño de barco & 2 \\
& N/C & 15 \\
Año 1800 & Subtotal & 58 \\
\hline \multirow{2}{*}{ Año 1850} & Comerciante & 46 \\
& Subtotal & 46 \\
\hline
\end{tabular}

TOTAL
NUMERO

17

133 


\section{CUADRO II \\ CLASIFICACION DE LOS PODERES SEGUN EL TIPO \\ DE OTORGANTE}

\section{O'TORGANTES NUMERO PORCENTAJES}

Año 1650

Individuos

14

82.35

Casas Comerciales

$3 \quad 17.65$

Ambos casos

$0 \quad 0.00$

Subtotal

17

Año 1700

Individuos

$3 \quad 60.00$

Casas Comerciales

20.00

Ambos casos

1

20.00

Subtotal

1

5

Año 1750

Individuos

35

60.34

Casas Comerciales

20

34.48

Ambos casos

3

5.18

Subtotal

58

Año 1800

Individuos

35

76.09

Casas Comerciales

11

23.91

Ambos casos

0

0.00

Subtotal

46

Año 1850

Individuos

4

57.14

Casas Comerciales

42.86

Ambos casos

Subtotal

3

0.00

0

7

TO'TAL

133 
CUADRO III

CLASIFICACION DE LOS OTORGANTES

POR SU VECINDAD O RESIDENCIA EN CADIZ

SITUACION

NUMERO

Año 1650

Vecinos

9

Residentes

8

Subtotal

17

Año 1700

Vecinos

Residentes

4

Subtotal

1

Año 1750

Vecinos

Residentes

52

Subtotal

58

Año 1800

Vecinos

Residentes

Subtotal

42

4

46

Año 1850

Vecinos

6

Residentes

1

Subtotal

TOTAL 


\begin{tabular}{llr}
\hline Año 1650 & Viajan & 6 \\
& No viajan & 11 \\
& Subtotal & 17 \\
\hline \multirow{2}{*}{ Año 1700} & Viajan & 1 \\
& No viajan & 4 \\
& Subtotal & 5 \\
\hline \multirow{2}{*}{ Año 1750} & Viajan & 4 \\
& No viajan & 54 \\
Año 1800 & Subtotal & 58 \\
\hline Año 1850 & Viajan & 1 \\
& No viajan & 45 \\
& Subtotal & 46 \\
\hline TOTAL & Viajan & 0 \\
\hline
\end{tabular}

\section{CUADRO V}

CLASIFICACION DE LOS APODERADOS POR SUS PROFESIONES

\begin{tabular}{lc} 
PROFESION & NUMERO \\
\hline No consta & 66 \\
Comerciante & 46 \\
Procurador & 11 \\
Capitán & 5 \\
Eclesiástico & 2 \\
Escribano & 1 \\
Militar & 1 \\
Contador Mayor & 1 \\
\hline TOTAL & 133 \\
\hline
\end{tabular}




\section{CUADRO VI \\ CIRCUITOS COMERCIALES}

Año 1650

América $\quad 14$

Península 3

Subtotal 17

Año 1700

Europa $\quad 1$

Península 3

Subtotal 4

Año 1750

América 29

Europa 10

Península 13

Eur.-Amér. 2

Subtotal $\quad 54$

Año 1800

América 14

Europa 5

Península 13

Eur.-Amér. 4

Subtotal 36

Año 1850

Europa 1

Península 3

Eur.-Amér. $\quad 1$

Subtotal 5

TOTAL

$116(39)$

(39) La cifra resultante no coincide con el total de poderes analizados porque hay diecisiete casos en los que la información en cuestión no es perceptiva por las propias características de la documentación (poderes no relacionados con la actividad comercial). E igual ocurre con el Cuadro VII. 


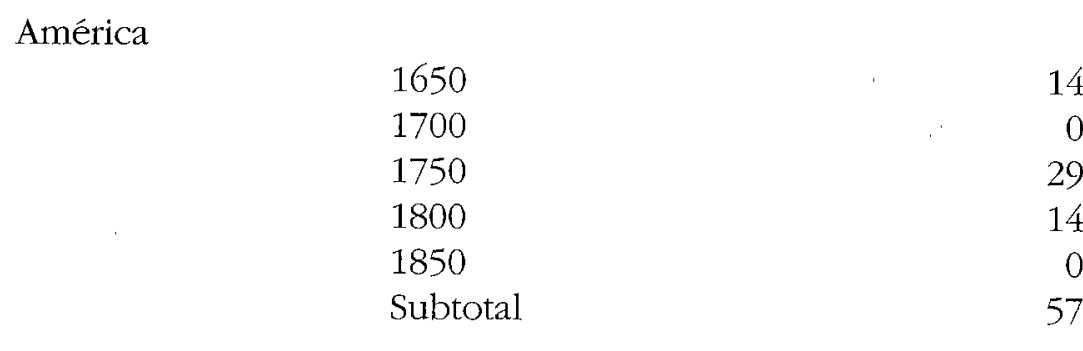

Europa

\begin{tabular}{lr}
1650 & 0 \\
1700 & 1 \\
1750 & 10 \\
1800 & 5 \\
1850 & 1 \\
Subtotal & 17 \\
\hline
\end{tabular}

Europa-América

1650

14

0

29

14

0

57

Europa-América

\begin{tabular}{ll}
1650 & 0 \\
1700 & 0 \\
1750 & 2 \\
1800 & 4 \\
1850 & 1 \\
Subtotal & 7 \\
\hline
\end{tabular}

Península

\begin{tabular}{llr}
1650 & 3 \\
1700 & 3 \\
1750 & 13 \\
1800 & 13 \\
& 1850 & 3 \\
& Subtotal & 35 \\
\hline TOTAL & & 116 \\
\hline
\end{tabular}




\section{CENSO DE OTORGANTES}

** 1650

Baltasar Jiménez de Espinosa

Baltasar de Breña y Cía.

Bartolomé Deecon

Claudio Salive

Fernando Díaz de Medina

Fernando de Arrespa

Juan Andrés

Juan Grande y Cía.

Juan de Valenzuela

Laureano de Figueroa

Luis Antonio de Villalta

Luis Guerra

Marcos de la Cruz

Martín Sánchez Morato

Pedro Bajo de Salazar

Pedro Ximénez de Ayllon

** 1700

Antonio Reynolds

Cristóbal Aine

Diego Corwn

Enrique Bertie

Francisco Sharracardinali

Guillermo Shaze

Guillermo Coguez

Isidro de Men

José Eaniel

José Garnier, Juan Olmiuz, Guillermo Con y Juan de Fas

José de la Haya

Juan Balas

Juan Baptista Reina

Juan Baptista Shazon

Juan Lamberto Fontena

Juan Rabrine y Cía.

Juan Shea y Woo 
Antonio Arnaud Hijo y Valles-Angel Malatesta

Arbore Hermanos

Bartolomé Joseph Bolta Hijos y Masnata

Carin Langton

Casaubon Behueye y Cía.

Diego Amiel

Diego de Medina y Ayala

Diego y Thomas Linch

Domingo Jerónimo de Otero

Domingo Martineli

Esteban Queruvini

Félix Almera

Francisco Arroy

Francisca Power

Francisco Jiménez

Francisco de Arteaga e Isidoro Comin.

Francisco de Arteaga y Verovia

Francisco de Rojas

Garvey y Barber

Garnier Mollet y Cía.

Garnier y Cornave

Girardon Amiel Fat y Cía.

Guillermo Mace e Hijo

Jaime Campins

José Angel Beyens

José Cain

José María Enrile

José de Calas Trujillo

Joseph Morando

Joseph y Juan Baptista Jordan

Juan Agustín Raimundo

Juan Andrés Prasca

Juan Ballen

Juan José Vélez

Juan Nicolás Vicioso

Juan Saige

La Pronnerie y Cía.

La Condamine y Cía.

Lorenzo de la Azuela y Velasco 
Lorenzo del Arco, Francisco de Arteaga e Isidoro Comin

Luis Gort y Juan Luis Marín

Luis de los Reyes Enríquez

Manuel Rivero

Miguel Sánchez

Nicolás Manuel Cranisbrogh

Pablo Capitanache

Pedro Capela

Pedro Pérez y Boyga

Pedro Verges

Pedro de Calas Trujillo

Roberto Main y Cía.

Salvador Font y Carbonell

Samuel Eyre

Verdui Vincent y Cía.

Vormerveh y Hoyv

** 1800

Angel Martín de Iribarren

Blas y Blas Pablo Pereira

Bocconi y Paille

Carlos Barzzoni

Diego de Garrido

Francisco Rosende

Francisco de Iriarte y Tomás de Urrutia

Gil Noeli

Guillermo Thompson y Cía.

Ignacio Casal

Joaquín Pedro Hinrichsen y Juan Francisco Bradamonde José Antonio de Durana

José Bron

José Coquelin

Juan Antonio Cobos

Juan Arduy

Juan Capdevielle

Juan Francisco Bradamonde

Juan José de Garay

Juan Miguel de Carlos

Juan Pascual García y Palma

Juan Pedro de Covarrubias 
Juan Walsh

Manuel Antonio de Vela

Manuel Butrón

Manuel Rancés

Martens y Von Lengercke

Matheo Melchent

Matías Mendiburu

Miguel Brickdale

Nicolás Joaquín Martens

Pando y Cía.

Pedro Luis Macey Anel

Pedro Perato

Pedro de Iriarte

Pedro de la Guerra

Ramón de Tovar

Santiago Antonio Reumei

Sebastián Martín

Sebastián y José Lasquetty Hijo

Simón de Agreda

Thomas y Henrique Linch y Cía.

** 1850

José Cereghetti

José Hurtado

Juan Grandis

Molet Hermanos

Stadd y Napp 